\title{
Türkiye'nin İklim Değişikliğine Bağlı Kuraklık Durumu
}

\author{
Emine Su Turan ${ }^{1, *}$ \\ ${ }^{1}$ Çukurova Üniversitesi, Mühendislik-Mimarlık Fakültesi, Çevre Mühendisliği Bölümü, 01330 Balcalı, Sarıçam, Adana.
}

\section{Özet}

Çeșitli insan faaliyetleri sebebiyle sanayi devriminden bu yana sera gazlarının atmosferdeki birikimleri hızla artmıștır. Atmosferde sera gazı birikimi sonucu oluşan sera etkisinin en önemli sonucu dünya ikliminin daha sicak ve daha değişken olmasına sebep olmasıdır. Diğer yandan iklim değişikliği, küresel veya bölgesel olması fark etmeksizin ekstrem hava ve iklim olaylarının sıklığında, şiddetinde, alansal dağılımında, uzunluğunda ve zamanlamasında da önemli değişikliklere neden olmaktadır. Küresel ve bölgesel olarak bir takım etkileri olduğu bilinen küresel iklim değişikliğinin potansiyel etkileri; temiz su kaynaklarl, tarım, orman, deniz seviyesi, enerji, insan sağlığı ve biyoçeşitlilik üzerinde yoğunlaşmaktadır. Ülkemizin, küresel iklim değişikliğinin olası etkileri açısından risk grubu ülkeler arasında yer aldiğı, gelecekte özellikle Akdeniz ve İç Anadolu Bölgelerimizin iklim değişikliğinden daha çok etkileneceği tahmin edilmektedir. Günümüzde en zararlı ve en az farkında olunan doğal afetlerden biri; kuraklıktır. İklimi yarı kurak olan ülkemizde yaşanan kuraklıklardaki artışın pek çok nedeni bulunmaktadır. İklim değişikliği ile beraber yă̆ışların olduğu yerlerle suya ihtiyacın olduğu yerlerin birbirinden çok farklı olması bunların başında gelmektedir. İklim değişikliği projeksiyonları sıcaklıkların ülke genelinde yükseleceği ve yă̆ışların özellikle ülkenin güney yarısında azalacă̆ını göstermektedir. Bu değişimlerin ülkemizin su kaynaklarını olumsuz yönde etkileyerek özellikle güneydeki havzalarda su potansiyelini azaltması kaçınılmazdır.

\section{$\underline{\text { Anahtar Sözcükler }}$}

Türkiye, İklim Değişikliği, Kuraklık

\section{Turkey's Drought Status Associated with Climate Change}

\begin{abstract}
Due to various human activities, the accumulation of greenhouse gases in the atmosphere has increased rapidly since the industrial revolution. The most important consequence of the greenhouse effect, which is the result of greenhouse gas accumulation in the atmosphere, is that the earth's climate is warmer and more variable. On the other hand, climate change, whether global or regional, causes significant changes in the frequency, intensity, area distribution, length and timing of extreme weather and climate events. Potential impacts of global climate change; known to have some impacts already both globally and locally, intensify on clean water resources, agriculture, forests, sea level, energy, human health and biodiversity. It is estimated that our country is among the countries of risk group in terms of the possible effects of the global climate change and will be affected more by the climate change in the future especially in the Mediterranean and Central Anatolia regions. One of the most harmful and least recognized natural disasters is drought. There are many reasons for the increase in drought in our semi-arid climate. It is at the top of these that climate change and precipitation are very different from places where water is needed. Climate change projections show that temperatures will rise throughout the country and precipitation will decrease especially in the southern half of the country. It is inevitable that these changes will affect the water resources of our country in the negative direction and decrease the water potential especially in the southern basins.
\end{abstract}

\section{$\underline{\text { Keywords }}$}

Turkey, Climate Change, Drought

\section{Giriş}

Bugünün iklim koşulları dikkate alındığında Türkiye'de küresel iklim değişikliğinin etkileri su kaynaklarının azalması, kuraklık, sıcak hava dalgaları, sellerdeki artış ve tarımda verimliliğin düşmesi olarak kendini göstermektedir. Hükümetlerarası İklim Değişikliği Paneli (Intergovernmental Panel on Climate Change, IPCC) tarafindan iklim değişikliğinin fiziksel temelleri ile etkileri üzerine 2013'te yayımlanan 5. Değerlendirme Raporu'nda (AR5) belirtilen, Akdeniz Havzası'nda ve Türkiye'de olması muhtemel değişiklikler durumun ne denli önemli olduğunu ortaya koymaktadır. Bunların başında ülkemizde yaşanan ve ileride de şiddetlenerek artacağı düşünülen kuraklık sıkıntısı gelmektedir. Kuraklık, sonuçları dikkate alındığında günümüzde insanoğlunun geleceğini tehdit eden en önemli küresel ve bölgesel çevre sorunlarının başında gelmektedir (Türkeş 2012a). Kuraklık, yağış miktarının uzun yıllar boyunca gerçekleşen yağışların ortalama değerinden daha az olması ile ortaya çıkan bir olaydır. 
Kuraklık, hem meydana getireceği zararlar bakımından hem de bu konuda farkındalığın yeterli seviyede olmaması açısından doğal afetler arasında en tehlikelilerin başında gelmektedir. Kuraklığın etki derecesi, süresi ve zamanının tahmini oldukça zor olup kuraklığın tesirleri, insan faaliyetleri ile de yakın ilişkilidir. Bazı durumlarda bir tek mevsim sürüp, sadece az bir alanı etkilerken iklim kayıtları kuraklığın bazı durumlarda yıllarca devam edebildiğini ve çok geniş alanları etkileyebildiğini göstermektedir. Su kaynakları su talebini karşılayamaz hale geldiğinde kuraklık ortaya çıkmaktadır.

Ülkemiz yarı kurak/yarı nemli orta enlem bölgesinde bulunmaktadır. Aynı bölgede bulunan pek çok ülke gibi dönemsel olarak bazı dönemlerde daha kurak iklim şartları hakimken bazı dönemlerde daha nemli iklim hakimdir (Şahin ve Kurnaz 2014). Türkiye'de 51 milyon hektarlık arazi kurak ve yarı kurak alan olarak değerlendirilmektedir. Bir başka ifade ile yarı kurak iklim koşulları ülkemizin \%37,3'ünde hakimiyet kurmuş durumdadır. Yağışın miktar ve dağılımında meydana gelebilecek değişiklikler, gerek su kaynakları, gerekse genelde yağışa bağımlı olan kuru tarım nedeniyle ciddi bir şekilde etkilerini hissettirebilmektedir. İnsanlık tarihi boyunca çeşitli kuraklık dönemleri meydana gelmiştir. Yarı kurak iklim bölgesinde yer alan Türkiye de geçmişte kuraklıkla karşı karşıya kalmış olup, kuraklık yakın dönemde de küresel iklim değişimi ile birlikte daha sık ve şiddetli gerçekleşeceğinden bugüne oranla daha çok tehlikeli olacaktır (Kadığlu 2012). İklim değişikliği, insan kaynaklı faaliyetler sebebiyle atmosferin bileşiminde veya arazi kullanımındaki değişiklikler sonucu oluşabilmektedir (Türkeş 2012b). İklim değişikliğinin etkisiyle su döngüsünde değişiklikler olmakta ve buna bağlı olarak kuraklık ve taşkın gibi doğal afetlerin meydana geliş sıklığı ve şiddetinde artışlar beklenmektedir (Çevre ve Şehircilik Bakanlı̆̆1 2012).

\section{Türkiye'de Kuraklığın Nedenleri}

Dünya üzerindeki 35 milyon $\mathrm{km}^{3}$ tatlı suyun sadece \% 0,3'ü ekosistem ve insani tüketime uygun tatlı su kaynaklarından oluşmaktadır. Türkiye'de ise toplam 95 milyar $\mathrm{m}^{3}$ yüzey suyundan \% 9 oranında faydalanılmakta olup, bunun \%79'u sulamada, \%14'ü içme suyunda, \%10'u ise sanayide kullanılmaktadır. Türkiye, sanılanın aksine su kıtlığı sınırında bir ülkedir. Türkiye'nin gereksinim duyacağı su miktarının, önümüzdeki 25 yılda günümüz su tüketiminin 3 katı olacağ1 öngörülmektedir (DSİ 2009; SYGM 2016).

Bugünün teknik ve ekonomik koşulları doğrultusunda, farklı maksatlar için kullanılabilecek yerüstü suyu potansiyeli yurt içindeki akarsulardan 95 milyar $\mathrm{m}^{3}$, komşu ülkelerden yurdumuza gelen akarsulardan 3 milyar $\mathrm{m}^{3}$ olmak üzere, ortalama yıllık toplam 98 milyar $\mathrm{m}^{3}$ tür. 14 milyar $\mathrm{m}^{3}$ civarında tespit edilen yeraltı suyu potansiyeli ile beraber ülkemizin kullanılabilir yerüstü ve yeraltı su potansiyeli yıllık toplam 112 milyar $\mathrm{m}^{3}$ olup, bu miktarın sadece $44 \mathrm{milyar}^{3} \mathrm{ü}$ kullanılmaktadır (DSİ 2009; Kahya 2017).

Türkiye'de kişi başına kullanılabilir su miktarı yıllık $1.300 \mathrm{~m}^{3}$ (günde yaklaşık 216 litre)'tür. Suyun değeri ve korunması söz konusu olduğunda, daha ziyade fazla su harcamamak, musluktan akan suyu verimli kullanmak, yağıŞ miktarları ve küresel iklim değişikliği gibi konular göz önünde bulundurulmaktadır. Ancak suyu doğru ve verimli kullanmanın yanı sıra bir ürünün üretimi aşamasında ne kadar su kullanıldığı da bilinmekle birlikte çoğu zaman dikkate alınmamaktadır. Bu anlamda su yalnızca doğrudan değil dolaylı olarak da fazla tüketilmektedir. Üreticilerin ve tüketicilerin kullandığı doğrudan ve dolaylı tüm su, "sanal su" olarak tanımlanır. Diğer bir ifadeyle bireyin, topluluğun ya da sektörün su ayak izi, "birey veya topluluk tarafından tüketilen ve sektör tarafından da üretilen her mal ve hizmetin üretilmesi için gereken toplam tatlı su hacmidir". Su ayak izi de hesaba katıldığında ülkemizde bir kişinin kullandığı su miktarı günde gerçekte 5.416 litreye kadar çıkmaktadır (Akın ve Akın 2007; Hoekstra vd. 2011; Muluk vd. 2013; Pegram vd. 2014). İklim şartlarının değişmemesinin mümkün olduğu durumda bile, yalnızca nüfus artışı sebebiyle 2050 yılında Türkiye'de kişi başına düşen su miktarının yılda $1.200 \mathrm{~m}^{3}$ civarında olacağ başka ifade ile ikliminin değiştiği ve nüfusunun hızla arttığı dikkate alındığında Türkiye'nin 2050 yılında su fakiri bir ülke olacağı öngörülmektedir (Kadığlu vd. 2017). Benzer şekilde SYGM (2016) raporuna göre MPI-ESM-MR Modeli RCP8.5 Senaryosu Türkiye'nin yüzeysel su potansiyelini 98 milyar $\mathrm{m}^{3}$ (yaklaşık \% 88) ve yeraltı suyu potansiyeli 14 milyar $\mathrm{m}^{3}$ (yaklaşık \%12) olarak hesaplamaktadır. Böylece günümüzde Türkiye'de kullanılabilir su miktarı kişi başına yıllık $1.300 \mathrm{~m}^{3}$ civarında olduğundan, Türkiye bu miktara kıyasla su azlığı yaşayan bir ülke konumundadır (SYGM 2016).

Ülkemizde sektörlere göre 2012 yılında gerçekleşen ve 2023 yılında beklenen su tüketimi miktarları ve yüzdeleri dikkate alındığında bugün Türkiye'nin kullanıma uygun durumdaki yüzey ve yeraltı su potansiyeli yıllık toplamı olan 112 milyar m³'lük suyun tamamı 2023 yılında mevcut ve tümüyle kullanılabilir durumda olmak zorundadır. Ancak bu miktarın tümünün kullanılamayacağı gibi küresel iklim değişikliği etkisiyle ülkemiz genelinde azalan yağış ile ülkemizin tüketilebilir yerüstü ve yeraltı su potansiyelinde önemli azalmalar olmaya başlamış ve bu azalma gelecekte de devam edecektir. 


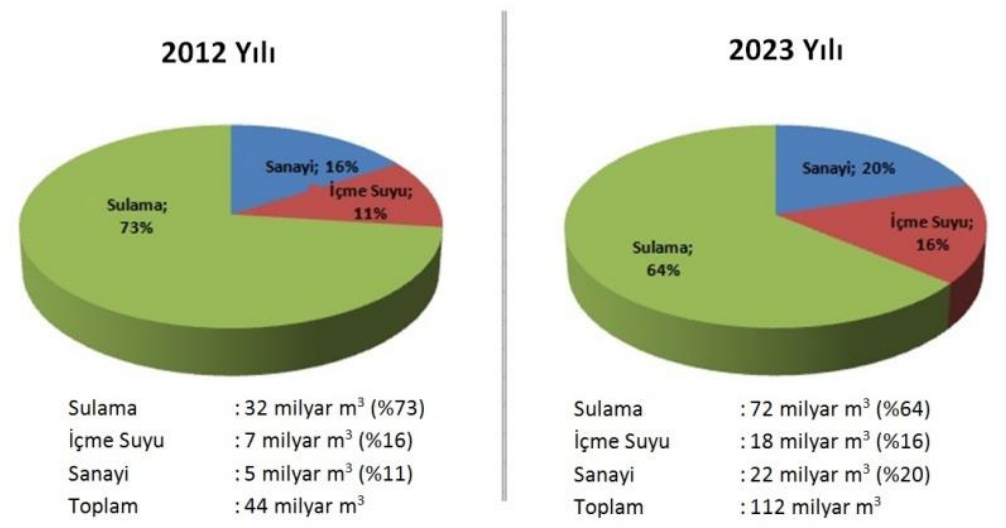

Şekil 1: Ülkemizde sektörlere göre 2012 yılında gerçekleşen ve 2023 yılında beklenen su tüketimi (SYGM 2016)

Türkiye'de kuraklı̆ga tesiri olan önemli faktörler arasında atmosferik koşullar, fiziki coğrafya faktörleri ve iklim koşulları bulunmaktadır. Yeryüzünde iklim özelliklerinin meydana gelişinde fiziki coğrafya faktörlerinin önemli tesirleri bulunmaktadır. Türkiye yüksek bir ülkedir ve ortalama yükseltisi 1100 m'den fazladır. Örnek olarak, Türkiye'nin deniz seviyesi ile $500 \mathrm{~m}$ arasında kalan alçak alanları ancak \% 17,5 kadar iken, 1000 m'den daha yüksek alanları ülke yüzölçümünün \% 55'den fazlasına tekabül etmektedir. Bunun ülkemizin iklimle ilgili koşullarına önemli ölçüde tesir edeceği kesindir. Ülkemiz, coğrafi konumu ve yapısı sebebiyle çok farklı iklim bölgelerine ve mikroklima alanlarına sahiptir. İklim ve bilhassa tarımsal üretimde en önemli etkiye sahip olan yağış faktörü, zamansal ve mekansal olarak büyük değişimler göstermektedir (Kapluhan 2013). Türkiye'nin pek çok bölgesinde hüküm süren bu kuraklık olayları ve su kıtlığı, tarım ve enerji üretimi için önemli olduğu kadar sulama, içme suyu, hidrolojik sistemler ve su kaynakları yönetimi açısından da oldukça önemlidir (Kapluhan 2013).

\section{Küresel İklim Değişikliğinin Su Kaynaklarına Etkisi}

Temiz, içilebilir kalitede ve insan sağlığına uygun su kaynaklarına erişim insan hayatı için vazgeçilmez gereksinimlerin başında gelmektedir. Bugün 1,3 milyar insan kullanıma sağlıklı ve kullanıma uygun suya erişebilecek durumda değildir. Bu insanlar öncelikle Orta Doğu, Kuzey ve Güney Afrika'da bulunmakla birlikte, dünya geneline yayılmışlardır. Bugün 19 ülke su kıtlığı veya su stresi sıkıntısına maruz kalmış durumdadır. 2025 yılında nüfus artışı ve ekonomik büyümeye paralel olarak bu sayının iki katına çıkacağı̈ ön görülmektedir (IPCC 1997). Küresel iklim değişikliğinin etkisiyle beraber, özellikle gelişmekte olan ve kurak bölgelerde bulunan ülkelerin su kıtlığı sıkıntısı daha fazla önemli hal alacaktır. 2 ila 2,5 ${ }^{\circ} \mathrm{C}$ seviyelerinde sıcaklık artışıyla beraber, 2,4 ila 3,1 milyar insanın temiz su kaynaklarına erişiminin riske gireceği belirtilmektedir (EC-DGE 2005). Sıcaklıkların artması, yağışların azalmasına paralel olarak nehirlerde debi azalması, kıyı bölgelerde tuzlu suların tatlı su kaynaklarına karışması ve fırtınaların çoğalması gibi durumlar su konusunda sıkıntılar yaşanmasına sebep olmaktadır (Doğan ve Tüzer 2011).

Türkiye küresel iklim değişikliğinin potansiyel etkileri açısından risk taşıyan ülkeler arasında bulunmaktadır. İklimde bugün gözlenebilen ve öngörülen değişiklikler, bilhassa başta su kaynaklarında azalma, kuraklık ve bunlara bağlı ekolojik bozulmalar, orman yangınları, erozyon, tarımsal üretkenlikte değişiklik olmak üzere sıcak dalgalarına bağlı ölümler ve vektör kaynaklı hastalıklarda artışlara kadar pek çok açıdan doğanın dengesinin değişmesine sebep olmaktadır (TBMM 2008). Bunun yanında küresel iklim değişikliği su kaynakları üzerinde, su arzında azalma, su kalitesinde düşüş, su kaynakları için rekabet gibi etkilere sebep olmaktadır (Doğan ve Tüzer 2011). İkliminin değiştiği ve nüfusunun hızla arttığı dikkate alındığında Türkiye'nin 2050 yılında su fakiri bir ülke olacağı tahmin edilmektedir (Kadıoğlu 2001).

Türkiye'de iklim değişikliği etkisiyle kuraklıklar sıklaşmakta, yaz aylarında sıcaklık artışı ve kış aylarında sıcaklıların düşüşleri gözlenmekte, toprağın niteliği değişmekte, yüzey sularında kayıplar ve seller meydana gelmektedir. Tüm bu etkiler gıda üretimi ve kırsal kalkınma için ihtiyaç duyulan su kaynaklarının varlı̆ğ üzerinde önemli bir tehdit oluşturmaktadır (Çevre ve Şehircilik Bakanlığı 2012). Günümüzde su kaynakları; küresel iklim değiş̧ikliğinin yanı sıra hızlı nüfus artışı, hatalı arazi kullanımı, kontrol edilmeyen kaçak ve kayıplar ve kirlenmenin de olumsuz etkisine maruz kalmaktadır. Ülkemiz açısından su kaynakları enerji ve tarımsal açıdan oldukça önemlidir. Geçmişte sulama ve enerji ihtiyacını karşılamak amacıyla çok sayıda su yapısı inşa edilmiş ve günümüzde de hala su yapısı inşa etmeye devam edilmektedir. Su yapılarının amaçları doğrultusunda kullanılması ve performans gösterebilmesi, ancak kuraklığın olmaması, bir başka ifade ile beklenen miktarda yağışın toprağa düşmesiyle mümkün olmaktadır (Kadıoğlu 2012). Tarımsal ve hidrolojik kuraklıkla mücadele için Türkiye'de kullanıma uygun su miktarı, DSİ tarafından yıllık olarak 234 milyar $\mathrm{m}^{3}$ brüt su potansiyelinin yaklaşık \%48'ine karşıllk gelmek üzere, toplam 112 milyar $\mathrm{m}^{3}$ olarak belirlenmiştir (Öztürk 2016). Stratejik bir kaynak olan yer altı suları da son yıllarda yoğun şekilde kullanılmakta ve su potansiyeli açısından önemli bir yer tutmaktadır. 
Türkiye'nin yeraltı su kaynakları, özellikle iklim değişikliğinin neden olabileceği suya bağlı olumsuzluklara karşı ülkemizin geleceğini teminat altına alabilecek nitelikteki en önemli "stratejik" su varlığıdır (SYGM 2016).

Günümüzde insan etkinliklerinin, su döngüsüne geri dönülmez biçimde müdahale etmesiyle artık kuraklık bir doğa olayı olmaktan çıkmıştır. Su kaynaklarının ekolojik dengeyi bozacak şekilde kullanılması; sulak alanlara ve akarsu yataklarına yanlış müdahaleler, yeraltı su depolarından kontrolsüzce su çekilmesi ve tarım ve hayvancılık için çok büyük miktarlarda su kullanılması küresel iklim değişikliği su kaynaklarında geri dönüşü olmayacak değişiklikler meydana getirmiștir. Günümüzde iklim değişikliği, nüfus artışı, kirlilik ve arazi kullanımıyla birlikte su döngüsüne en büyük baskıyı yapan etken olarak görülmektedir (Kang vd. 2009).

\section{Küresel İklim Değişikliği ve Kuraklık}

IPCC 4. Değerlendirme Raporu'nun (AR4) temelini oluşturan yüksek emisyon senaryolu (A2) model simülasyonları yüzyılın sonuna yaklaşıldığında Türkiye'de yıllık sıcaklıkların bugüne oranla $3,1-5,2{ }^{\circ} \mathrm{C}$ civarında artacağını tahmin etmektedir. Daha ziyade kıyı bölgelerinde, bilhassa Ege, Marmara ve Karadeniz bölgelerinde artışın düşük kalacağı tahmin edilmektedir. Akdeniz, Güneydoğu Anadolu ve Doğu Anadolu bölgelerinde yüksek artışın daha çok olacağı beklenmektedir. Ülke genelinde yağışlar azalacak olup, kış mevsiminde yaz mevsimine göre daha az artış beklenmektedir. Karadeniz ve Marmara bölgelerinde yağış değişiminin az olacağı öngörülürken, bilhassa Akdeniz bölgesi ile Ege bölgesinin güneyinde daha fazla olmakla birlikte \% 30'lara ulaşan oranlarda yağış azalımı olacaktır. Bölgesel iklim modeliyle gerçekleştirilen yüksek çözünürlüklü iklim değişikliği simülasyonları ile küresel model projeksiyonları sonuçları genel itibariyle uyuşmaktadır (Şen 2013).

Küresel iklim değişikliğinin, hem küresel hem de bölgesel olarak bir dizi tesirlerinin ortaya çıtığ ve bu etkilerin gün geçtikçe artacağı bilinmektedir. Küresel iklim değişikliğinin temiz su kaynakları, tarım, orman ve bitki örtüsü, deniz seviyesi, enerji, insan sağlığ 1 ve biyoçeşitlilik konusunda önemli tesirleri olmaktadır. Küresel iklim değişikliğinin sosyal ve ekonomik olarak birbirine etki eden etkilerinin de olması kaçınılmazdır (Doğan ve Tüzer 2011).

Kuraklık meteorologların, hidrologların, tarımcıların, iklim bilimcilerin, sosyal bilimcilerin ve toplumun bütün kesimlerinin hakim olması ve çözümü üzerine beraber çalışılması gereken bir konudur. Gün geçtikçe süresi ve şiddeti artan kuraklık olayları gibi iklimin değişken olması ve iklim değişikliği ile bağlantılı faktörler, arazinin çölleşmeden etkilenebilirliği ve çölleşmenin hızlanmasında artışa neden olabilmektedir. Bugün çöllerin ve çölleşmeye meyilli alanların olduğu, çok kurak, kurak, yarı-kurak ve kuru/yarı-nemli araziler, yeryüzündeki karalarının \%47'sini oluşturmaktadır (Tablo1; Şekil 2). Ülkemizde ise, çölleşmeye meyilli yar1-kurak ve kuru/yarı-nemli araziler, ülke topraklarının \% 35 'ini oluşturmakta; yarı-nemli iklim şartları ile beraber bu oran yaklaşı \%60'a ulaşmaktadır (Tablo 2).

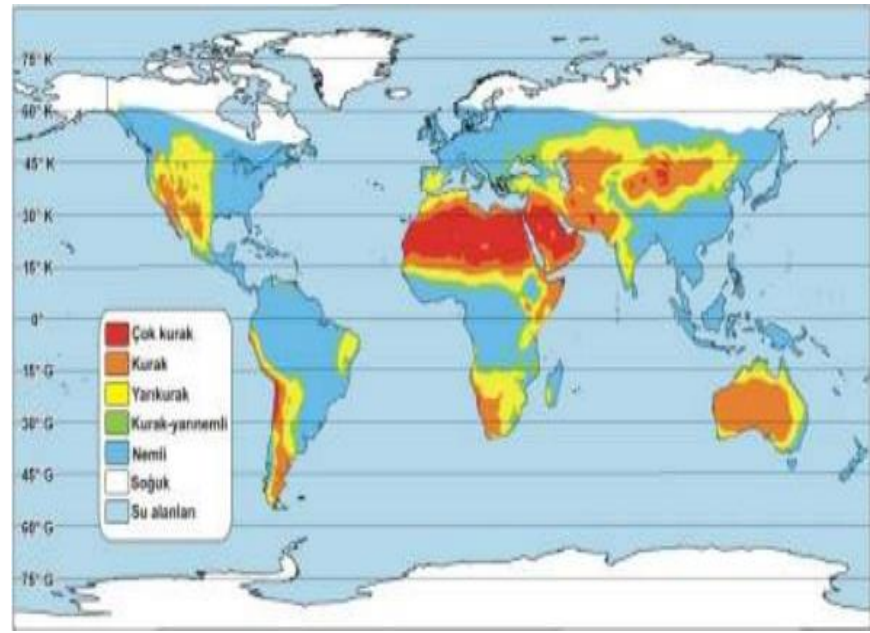

Şekil 2: Birleşmiş Milletler Çölleşme ile Savaşım Sözleşmesi kuraklık indisine göre iklim çeşitlerinin yerküre karaları üzerindeki coğrafi dağılımı (Türkeş 2012a)

Tablo 1: Yeryüzündeki kurak arazilerin kapladığı alanlar (Türkeş 2012a)

\begin{tabular}{|l|c|c|}
\hline Sınıflandırma & Kuraklık İndisi (Ki்) & Alan(\%) \\
\hline Çok Kurak & $\mathrm{KI}<0.05$ & 7,5 \\
\hline Kurak & $0,05<\mathrm{KI}<0.20$ & 12,1 \\
\hline Yar1 Kurak & $0,20<\mathrm{KI}<0.50$ & 17,7 \\
\hline Kuru- Yarı Nemli & $0,50<\mathrm{KI}<0.65$ & 9,9 \\
\hline
\end{tabular}


Tablo 2: Kuraklık indisi değerleri 0,80'den ve 0,65'den küçük olan istasyonların Türkiye coğrafi bölgelerine göre dağılışı (Türkeş 2012a)

\begin{tabular}{|c|c|c|c|c|}
\hline Coğrafi Bölge & \multicolumn{2}{|c|}{$K \dot{I}<0.80$} & \multicolumn{2}{|c|}{$K \dot{I}<0.65$} \\
\hline (İstasyon Sayısı) & Say1s1 & $\%$ 'si & Say1s & $\%$ 'si \\
\hline Karadeniz (15) & 7 & 46,7 & 4 & 26,6 \\
\hline Marmara (15) & 8 & 53,3 & 1 & 6,7 \\
\hline Ege (11) & 7 & 63,6 & 1 & 9,1 \\
\hline Akdeniz (15) & 8 & 53,3 & 6 & 40,0 \\
\hline Güneydoğu Anadolu (8) & 8 & 100,0 & 5 & 62,5 \\
\hline İç Anadolu (12) & 10 & 83,3 & 9 & 75,0 \\
\hline Doğu Anadolu (14) & 5 & 35,7 & 5 & 35,7 \\
\hline Türkiye (90) & 53 & 58,9 & 31 & 34,4 \\
\hline
\end{tabular}

İklim, iklim değişikliği ve kurak koşullar ile çölleşme arasındaki bağlantı açık olmasına rağmen, Ülkemizde yapılan Türkiye'de Birleşmiş Milletler Çölleşme ile Savaşım Sözleşmesi'ne (BMÇSS) yönelik ulusal ve uluslararası düzeydeki çalışmalarda, yayınlarda ve ulusal rapor ile eylem planlarında (örn. MoEF 2006), çoğunlukla konu çeşitli insan etkinlikleri ve doğal faktörler ile erozyon sebebiyle oluşan arazi degradasyonu bakımından değerlendirilmektedir. Konunun iklimdeki değişmeler/ iklim değişikliği ve kuraklık ilişkisi ve boyutu çoğu zaman göz ardı edilmektedir (Türkeş 2012a).

Ülkemizde iklim değişikliği ile beraber, kuraklık ve sel baskınları tehditlerinin bazı endüstri dalları ve toplumlara negatif etkiler yapacağı öngörülmektedir. Tablo3'te etki örnekleri ile etkilenebilecek sektörler ve bölgeler bulunmakta olup, ülkemizde kuraklığa, sellere ve kendiliğinden çıkan yangınlara sebep olan iklimsel etkiler temelinde göreceli olarak sektörlere ve bölgelere özel, etkilerin şiddeti ortaya konulmuştur (Çevre ve Şehircilik Bakanlığı 2012).

Tablo 3: Iklim değişikliğinin etkileri ve Türkiye'de etkilenebilirlik arz eden sektörler/bölgeler (Çevre ve Şehircilik Bakanlığı 2012).

\begin{tabular}{|c|c|c|c|}
\hline Etkiler & Şiddet & Etkilenebilecek Bölgeler & Etkilenebilecek Sektörler/Temalar \\
\hline Nehir/hava rejimlerinin değişmesi & Düşük & Tüm bölgeler & \begin{tabular}{|c|} 
Ekosistem hizmetleri ve biyolojik \\
çeşitlilik
\end{tabular} \\
\hline Azalan yüzey suları & Orta & Batı Anadolu Bölgesi & Tarım, su dağıtım şebeke altyapısı \\
\hline \multirow{2}{*}{ Artan kullanma suyu kıtlığı } & Yüksek & $\begin{array}{c}\text { İstanbul, Ankara, Aydın, } \\
\text { Nevşehir, Bursa }\end{array}$ & Kentsel alanlar \\
\hline & Orta & $\begin{array}{l}\text { Afyon, İzmir, Kayseri, } \\
\text { Muğla, Manisa }\end{array}$ & Tarım, sanayi, enerji \\
\hline Sel & Orta & $\begin{array}{c}\text { Karadeniz ve Güneydoğu } \\
\text { Anadolu Bölgeleri }\end{array}$ & $\begin{array}{c}\text { Tarım çiftçisinin ayakta kalması, } \\
\text { insan sağlığı } \\
\end{array}$ \\
\hline Toprak kayb1/ tuzluluk & Düşük & $\begin{array}{l}\text { Akdeniz, Karadeniz ve Ege } \\
\text { Bölgeleri Güneydoğu } \\
\text { Anadolu Bölgesi }\end{array}$ & $\begin{array}{c}\text { Turizm, ekosistem hizmetleri, } \\
\text { biyolojik çeşitlilik, deniz } \\
\text { ürünleri }\end{array}$ \\
\hline $\begin{array}{c}\text { Topraksızlaşma/toprağın niteliğini } \\
\text { kaybetmesi }\end{array}$ & Orta & Güney Batı Anadolu & $\begin{array}{l}\text { Tarım çiftçisinin ayakta } \\
\text { kalması, gıda güvencesi, derin } \\
\text { olmayan göller ve sulak alanlar }\end{array}$ \\
\hline Kiyı erozyonu & Düşük & Karadeniz Bölgesi & Balıkçılık, işsizlik \\
\hline Denizsel ekosistemin bozulması & Düşük & $\begin{array}{c}\text { Akdeniz, Ege, Karadeniz } \\
\text { Bölgeleri } \\
\end{array}$ & $\begin{array}{l}\text { Ekosistem hizmetleri, biyolojik } \\
\text { çeşitlilik }\end{array}$ \\
\hline Orman yangınları & Orta & Batı Anadolu & Turizm, tarım \\
\hline \begin{tabular}{|c|} 
Türlerin yaşamak için başka alanlara \\
göç etmesi
\end{tabular} & Düşük & Akdeniz Bölgesi & Turizm, tarım, gıda güvencesi \\
\hline Azalan tarımsal prodüktivite & Orta & Akdeniz ve Ege Kıyıları & Tarım (istihdam), gıda güvencesi \\
\hline Azalan hidroenerji potansiyeli & Düşük & Akdeniz Bölgesi & Enerji, sanayi \\
\hline Azalan deniz ürünleri üretimi & Düşük & Akdeniz Bölgesi & $\begin{array}{c}\text { Tarım, gida güvencesi, su } \\
\text { dağıtım şebekesi }\end{array}$ \\
\hline
\end{tabular}


Türkiye’nin İklim Değişikliği Birinci Ulusal Bildiriminde ulusal ve uluslararası model çalışmalarıyla ülkemizde yakın tarihte sıcaklıkların ve kuraklığın artacağı, yağışların düzensiz olacağ 1 iklim koşullarının yaşanacağı belirtilmiştir. Muhtemel yeni koşullarda en büyük riskin su kaynaklarının azalmasıyla ilgili olacağı beklenmektedir. Türkiye'de kuraklık ve su kıtlığı tarım ve enerji sektörlerine ek olarak pek çok sektör için tehdit durumuna gelmiştir (Çevre ve Şehircilik Bakanlığg1 2012).

\section{Sonuç}

Ülkemizin, nüfus artışı ile birlikte küresel iklim değişikliğinin de etkileri sonucu daha kurak bir iklime sahip olacağ1 düşünüldüğünde 2050 yılında Türkiye'de kişi başına düşen su miktarının yılda $1.200 \mathrm{~m}^{3}$ civarında olacağ tahmin edilmektedir. Bir başka ifade ile ikliminin değiştiği ve nüfusunun hızla arttığı dikkate alındığında Türkiye'nin 2050 yılında su fakiri bir ülke olacağı öngörülmektedir. Bunun yanında ülkemizde suyun kısıtlı, yağışların bazı bölgeler dışında miktar ve dağılımının düzensiz olduğu, büyük şehirlerde ve tarımsal üretimde suyun kısıtlı bulunduğu, içme, kullanma ve sulama suyu kalitesinin gün geçtikçe artan sanayi ve diğer faaliyetler sonucu oluşan çevre kirlenmesi neticesinde düştüğü ve küresel iklim değişikliğinin etkilerinin arttığı düşünüldüğünde, Türkiye'nin çok yakın bir tarihte kuraklığın şiddetini bugüne oranla çok daha yüksek hissedeceği aşikardır.

Ülkemizdeki iklimin kuraklık yönündeki olumsuz değişimi ve su taleplerinin artması; kuraklık riskinin önemli derece yüksek olduğunu ortaya koymaktadır. Kuraklığın şiddetlenmesi ile sınırları aşan nehirlerin kullanımı dahil pek çok uluslararası ve ulusal su kaynağının paylaşımı ve yönetimi daha da zorlaşabilecektir. İklim değişikliğine bağlı olarak şiddetlenerek artması beklenen kuraklık, sel ve ortalama sıcaklıklardaki artışlar taşıyıcı (yiyecek ve sudan) kaynaklı hastalıklara sebep olarak sağlık üzerinde de toplumun büyük bir kısmı risk altına sokarak etkili olacaktır. Benzer şekilde kuraklık; eko sistem göçü, gıda ve su kıtlığı, yetersiz beslenmeye sebep olarak insan sağlına zarar vermekte, bilhassa düşük gelir seviyesindeki kişiler, yaşlılar ve çocukları önemli ölçüde olumsuz etkilemektedir. Sıcaklık artışlarıyla birlikte yaşanacak seller ve kuraklık temiz suya erişimi olumsuz etkilemekte, özellikle ishalli hastalıklarda (ör. Kolera) artışa, fiziksel yaralanma ve yetersiz beslenmeye neden olabilmektedir (Sağlık Bakanlığı 2010). Bütün bunlar, Türkiye'nin ileride karşılaşabileceği tehlikenin boyutlarının ne derece önemli olduğunu ortaya koymaktadır.

Türkiye'de iklim değişikliğinin etkilerine karşı uyum politikalarında daha ziyade su kıtlığındaki artışlara ve buna bağlı olarak kuraklık sorunlarına odaklanılmıştır. Ülkemizde kuraklık, iklimle ilgili felaketler sıralamasında ilk sıralarda bulunmaktadır. Kuraklıkla ilgili afet uyarı politikaları ve sistemleri oluşturulmaya, gerçekçi su politikaları oluşturulmaya çalışılmaktadır. Kuraklık, etkileri uzun vadede ortaya çıkan genellikle yavaş gelişen ve zaman alan bir süreçte gerçekleşen bir afettir. Kuraklığın bu özellikleri kuraklığa karşı alınması gereken önlemlerin de kuraklık meydana gelmeden ve kuraklığın yıllar boyu süren etkilerini uzun vadede ortadan kaldıracak nitelikte olması gerektiğini göstermektedir. Bu yüzden kuraklık yönetiminde kuraklığın uzun süren etkilerini kontrol altında tutabilmek için kriz yönetimi gibi kuraklığa karşı son dakikada alınan tedbirlerden ziyade risk yönetimi çok daha önemlidir. Bu sebeple ülkemizde temelini risk yönetiminin oluşturduğu kuraklık planlaması ulusal ve bölgesel bazda sürdürülmelidir.

\section{Kaynaklar}

Akın M., Akın G., (2007), Suyun önemi, Türkiye'de su potansiyeli, su havzaları ve su kirliliği, Ankara Üniversitesi Dil ve TarihCoğrafya Fakültesi Dergisi, 47(2), 105-118.

Çevre ve Şehircilik Bakanlığı, (2017), Türkiye'nin iklim değişikliği uyum stratejisi ve eylem planı, T.C. Çevre ve Şehircilik Bakanlığı, Çevre Yönetimi Genel Müdürlüğü, İklim Değişikliği Dairesi Başkanlığı, http://webdosya.csb.gov.tr/db/destek/ editordosya/Iklim_Degisikligi_Uyum_Stratejisi_ve_Eylem_Plani.pdf, [Erişim 11 Ekim 2017].

Doğan S., Tüzer M., (2011), Küresel iklim değişikliği ve potansiyel etkileri, C.Ü. İktisadi ve İdari Bilimler Dergisi, 12(1), 21-34.

DSİ, (2009), T.C. Çevre ve Orman Bakanlığı Devlet Su İşleri, Su ve DSİ, 5. Dünya Su Forumu, İstanbul, http://www.dsi.gov.tr/docs/sempozyumlar/kuraklık-ve-su-yönetimi-toplantısı-ankara.pdf?sfvrsn=2, [Erişim 19 Ekim 2017].

EC-DGE, (2005), The Impacts and Costs of Climate Change, European Commission - Directorate General Environment, http://ec.europa.eu/environment/climat/pdf/final_report2.pdf, [Erişim 21 Ekim 2017].

Frederick K.D., Major D., (1997), Climate change and water sources, Climatic Change 37(1), 7-23.

Hoekstra A.Y., Chapagain A.K., Aldaya M.M., Mekonnen M.M., (2011), The water footprint assessment manual: setting the global standard, Earthscan, London, UK, 228ss.

IPCC, (1997), The Regional Impacts of Climate Change: An Assessment of Vulnerability, IPCC Special Report, https://www.ipcc.ch/pdf/special-reports/spm/region-en.pdf, [Erişim 27 Ekim 2017].

IPCC, (2007), Climate Change 2007: Summary for Policymakers, In: Climate Change 2007: The Physical Science Basis. Contribution of Working Group I to the Fourth Assessment Report of the Intergovernmental Panel on Climate Change [Solomon, S., D. Qin, M. Manning, Z. Chen, M. Marquis, K.B. Averyt, M.Tignor and H.L. Miller (eds.)]. Cambridge University Press, Cambridge, United Kingdom and New York, NY, USA.

IPCC, (2013), Climate Change 2013: The Physical Science Basis. Contribution of Working Group I to the Fifth Assessment Report of the Intergovernmental Panel on Climate Change [Stocker, T.F., D. Qin, G.-K. Plattner, M. Tignor, S.K. Allen, J. Boschung, A. Nauels, Y. Xia, V. Bexand P.M. Midgley (eds.)]. Cambridge UniversityPress, Cambridge, United Kingdomand New York, USA.

Kadıŏlu M., (2001), Kuraklık kıranı, Güncel Yayıncılık, İstanbul, 125ss. 
Kadığlu M., (2012), Türkiye'de iklim değişikliği risk yönetimi, Türkiye’nin İklim Değişikliği II. Ulusal Bildiriminin Hazırlanması Projesi Yayını, 172ss.

Kadıŏlu M., Ünal Y., İlhan A., Yürük C., (2017), Türkiye'de iklim değişikliği ve tarımda sürdürülebilirlik, Türkiye Gıda ve İcecek Sanayi Dernekleri Federasyonu, http://www.hidropolitikakademi.org/wp-content/uploads/2017/11//klimDegisikligiRaporumin.pdf, [Erişim 23 Ekim 2017].

Kahya E., (2017), Hidroloji, https://tr.scribd.com/presentation/135160715/1-ppt. [Erişim 27 Ekim 2017].

Kang Y., Khan S., Ma X., (2009), Climate changeimpacts on cropyield, crop water productivity and food security - A review, Progress in Natural Science, 19: 1665-1674.

Kapluhan E., (2013), Türkiye'de kuraklık ve kuraklı̆̆ın tarıma etkisi, Marmara Coğrafya Dergisi, 27, 487-510.

MoEF, (2006), Turkey's National Report on the Implementation Processes of the Convention, May1s 2006, Ankara http://www.unccd.int/cop/reports/northmed/national/2006/turkey-eng.pdf, [Erişim $01 \mathrm{Kas} ı m$ 2017].

Muluk C.B., Kurt B., Turak A., Türker A., Çalışkan M.A., Balkız O., Gümrükçü S., Sarıül G., Zeydanlı U., (2013), Türkiye'de suyun durumu ve su yönetiminde yeni yaklaşımlar: çevresel perspektif, İş Dünyası ve Sürdürülebilir Kalkınma Derneği - Doğa Koruma Merkezi, http://www.skdturkiye.org/files/yayin/Turkiyede-Suyun-Durumu-ve-Su-Yonetiminde-Yeni-Yaklasimlar-Raporu.pdf, [Erişim 18 Ekim 2017].

Öztürk İ., (2016), İklim Değişikliğinin Su Kaynaklarına Etkisi Projesi Hidrolojik Modelleme ve Değerlendirme Sunumu, http://suyonetimi.ormansu.gov.tr/Libraries/su/Iklim_Degisikliginin_Turkiye_nin_Su_Kaynaklarina_Etkisi_Prof_Dr_\%C4\%B0zz et_\%C3\%96ZT\%C3\%9CRK_3.sflb.ashx, [Erișim 26 Ekim 2017].

Pegram G., Conyngham S., Aksoy A., Divrak B.B., Öztok D., (2014), Türkiye'nin su ayak izi raporu: su, üretim ve uluslararası ticaret iliş̧kisi, WWF-Türkiye, http://d2hawiim0tjbd8.cloudfront.net/downloads/su_ayak_izi_raporweb.pdf, [Erişim 09.10.2017].

Sağlık Bakanlığı, (2010), Türkiye'nin hava kirliliği ve iklim değişikliği sorunlarına sağlık açısından yaklaşım, Türkiye Cumhuriyeti Sağlık Bakanlığı Temel Sağlık Hizmetleri Genel Müdürlüğü, http://www.ihsm.gov.tr/ihsmkronik/dosya/turkiyenin_havakirliligi_ veiklimdegisikligi_ sorunlari.pdf, [Erişim 09 Ekim 2017].

SYGM, (2016), T.C. Orman ve Su İşleri Bakanlığı Su Yönetimi Genel Müdürlüğü (SYGM) Taşkın ve Kuraklık Yönetimi Dairesi Başkanlığı, Iklim Değişikliğinin Su Kaynaklarına Etkisi Projesi, Proje Nihai Raporu, Ankara.

Şahin Ü., Kurnaz L., (2014), İklim değişikliği ve kuraklık, Sabancı Üniversitesi, İstanbul Politikalar Merkezi, Stiftung Mercator Girişimi, http://ipc.sabanciuniv.edu/wp-content/uploads/2014/10/IPM_KuraklikRaporu_24.10.14_web_rev2.pdf, [Erişim 11 Ekim 2017].

Şen Ö.L., (2013), Türkiye'de iklim değişikliğinin bütünsel resmi, Türkiye'de İklim Değişikliği Kongresi (TİKDEK 2013), 3-5 Haziran, İstanbul.

TBMM, (2008), Küresel ısınmanın etkileri ve su kaynaklarının sürdürülebilir yönetimi konusunda kurulan meclis araştırması komisyonu raporu, Türkiye Büyük Millet Meclisi, https://www.tbmm.gov.tr/sirasayi/donem23/yil01/ss138.pdf, [Erişim 23 Ekim 2017].

Türkeş M., (2012a), Kuraklık, çölleşme ve birleşmiş milletler çölleşme ile savaşım sözleşmesi'nin ayrıntılı bir çözümlemesi, Marmara Avrupa Araştırmaları Dergisi, 20(1), 7-55.

Türkeş M., (2012b), Türkiye'de gözlenen ve öngörülen iklim değişikliği, kuraklık ve çölleşme, Ankara Üniversitesi Çevre Bilimleri Dergisi, 4(2), 1-32. 